\title{
Physician Assistants' Views of Direct-to-Consumer Advertising Effects during Patient Encounters
}

Anna A. Filipova

University of Wisconsin Oshkosh, filipova@uwosh.edu

Follow this and additional works at: https://nsuworks.nova.edu/ijahsp

Part of the Medicine and Health Sciences Commons

This Manuscript has supplementary content. View the full record on NSUWorks here: https://nsuworks.nova.edu/ijahsp/vol18/iss2/2

\section{Recommended Citation}

Filipova AA. Physician Assistants' Views of Direct-to-Consumer Advertising Effects during Patient Encounters. The Internet Journal of Allied Health Sciences and Practice. 2020 Jan 01;18(2), Article 2.

This Manuscript is brought to you for free and open access by the College of Health Care Sciences at NSUWorks. It has been accepted for inclusion in Internet Journal of Allied Health Sciences and Practice by an authorized editor of NSUWorks. For more information, please contact nsuworks@nova.edu. 


\title{
Physician Assistants' Views of Direct-to-Consumer Advertising Effects during Patient Encounters
}

\begin{abstract}
Purpose: Direct-to-consumer advertising (DTCA) has become an important tool for disseminating drug information that directly impacts the patients and providers in the delivery of health care. Limited research shows that DTCA has both benefits and drawbacks that impact public health. However, there is a paucity of empirical evidence of the effects of DTCA information discussed during an office visit from the perspective of physician assistants. The purpose of the study was to examine physician assistants' general views of DTCA benefits and drawbacks, as well as the effects DTCA information discussed during patient encounters on physician assistant-patient relationship, physician assistants' prescriptive authority and time efficiency of the visit.

Methods: A cross-sectional design was used to survey physician assistants in a single U.S. Midwestern state. A random sample of 860 of the state's 4,483 physician assistants was drawn. The final sample consisted of 161 PAs (18.72\%). Of these, 149 PAs (93\%) had experience with discussing DTCA during an office visit. Pearson's chi-squared analysis, logistic regression and multinomial logistic regression analyses were used to measure the associations between the variables.

Results: Of the 161 physician assistants, most thought that DTCA drove up drug costs (76\%), promoted unnecessary fear of side effects (71\%), and did not provide a balanced view of risks and benefits of the product (64\%). Conversely, most agreed that DTCA alerted patients to new therapies $(74 \%)$ and did not create a conflict between the physician assistant and supervising physician (71\%). Of the 149 physician assistants who experienced discussion about DTCA during a visit, $49 \%$ reported that patients did so because they wanted a drug; $62 \%$ deemed patients' requests inappropriate; and $74 \%$ viewed DTCA as worsening the time efficiency. Worsened efficiency was associated with the patient wanting a test, bringing a printed advertisement, and the advertisement not being relevant. Worsened physician assistant-patient relationship was associated with challenged authority.

Conclusions: The study highlights the need to enhance dialogue between the physician assistant and the supervising physician about patient needs, to provide targeted DTCA educational training opportunities that sharpen communication and interpersonal skills, and to incorporate physician assistants' perspectives in future guidelines governing DTCA.
\end{abstract}

\section{Author Bio(s)}

Anna A. Filipova, Ph.D., is a Professor in the Public Administration Department at the University of Wisconsin Oshkosh in Oshkosh, Wisconsin. She is currently Department Chairperson and Master of Public Administration program Coordinator. Dr. Filipova teaches and conducts research in healthcare management, health administration law and ethics and healthcare policy.

\section{Acknowledgements}

This work was supported by the University of Wisconsin Oshkosh's Office of the Provost and Vice Chancellor Faculty Development Program under Research Project Grant No. FDR1088. 


\title{
IUAHSP \\ The Internet Journal of Allied Health Sciences and Practice \\ Dedicated to allied health professional practice and education
}

Vol. 18 No. 1 ISSN 1540-580X

\section{Physician Assistants' Views of Direct-to-Consumer Advertising Effects During Patient Encounters}

\author{
Anna A. Filipova \\ University of Wisconsin Oshkosh
}

United States

\begin{abstract}
Purpose: Direct-to-consumer advertising (DTCA) has become an important tool for disseminating drug information that directly impacts the patients and providers in the delivery of health care. Limited research shows that DTCA has both benefits and drawbacks that impact public health. However, there is a paucity of empirical evidence of the effects of DTCA information discussed during an office visit from the perspective of physician assistants. The purpose of the study was to examine physician assistants' general views of DTCA benefits and drawbacks, as well as the effects DTCA information discussed during patient encounters on physician assistant-patient relationship, physician assistants' prescriptive authority and time efficiency of the visit. Methods: A cross-sectional design was used to survey physician assistants in a single U.S. Midwestern state. A random sample of 860 of the state's 4,483 physician assistants was drawn. The final sample consisted of 161 PAs (18.72\%). Of these, 149 PAs (93\%) had experience with discussing DTCA during an office visit. Pearson's chi-squared analysis, logistic regression and multinomial logistic regression analyses were used to measure the associations between the variables. Results: Of the 161 physician assistants, most thought that DTCA drove up drug costs $(76 \%)$, promoted unnecessary fear of side effects $(71 \%)$, and did not provide a balanced view of risks and benefits of the product (64\%). Conversely, most agreed that DTCA alerted patients to new therapies (74\%) and did not create a conflict between the physician assistant and supervising physician (71\%). Of the 149 physician assistants who experienced discussion about DTCA during a visit, $49 \%$ reported that patients did so because they wanted a drug; $62 \%$ deemed patients' requests inappropriate; and 74\% viewed DTCA as worsening the time efficiency. Worsened efficiency was associated with the patient wanting a test, bringing a printed advertisement, and the advertisement not being relevant. Worsened physician assistant-patient relationship was associated with challenged authority. Conclusions: The study highlights the need to enhance dialogue between the physician assistant and the supervising physician about patient needs, to provide targeted DTCA educational training opportunities that sharpen communication and interpersonal skills, and to incorporate physician assistants' perspectives in future guidelines governing DTCA.
\end{abstract}

Keywords: physician assistant, direct-to-consumer advertising, physician assistant-patient relationship, efficiency of care, prescriptive authority 


\section{INTRODUCTION}

Direct-to-consumer advertising (DTCA) has become an important tool for disseminating drug information that directly affects the patients and providers in the delivery of health care. ${ }^{1-4}$ Since 2012 , DTCA spending has increased by $62 \%$, reaching 6.4 billion in 2016. ${ }^{2}$ Proposals to completely ban DTCA have not been supported by policy makers; instead, the focus has been on regulation. ${ }^{1,3}$ Limited empirical evidence shows that DTCA has both benefits and drawbacks that impact public health. ${ }^{1}$ On one hand, DTCA was thought to empower patients to voice their health concerns to providers and encourage patients to follow the doctor's instructions. ${ }^{4,6,7}$ It also improved the provider-patient relationship and raised awareness of underdiagnosed and treatable conditions. $4-6,8,10$ On the other hand, DTCA was believed to provide limited information of the drug risks and limited a patient's willingness for lifestyle changes. ${ }^{4,7,8}$ It also increased the time for the provider to explain DTCA information and increased patient dissatisfaction when not given a requested prescription. $4,8,9$ DTCA was also perceived to lead to increased drug costs. $4,7,8$

Empirical research has also found that DTCA acted as a catalyst, influencing patients to seek information about a drug's side effects, effectiveness, and appropriateness for use. ${ }^{11}$ Therefore, DTCA may present an opportunity for enhancing provider-patient communication, shared decision-making and relationship. ${ }^{11}$ Murray et al. found the following factors associated with an improved provider-patient relationship as a result of DTCA information discussed during a visit: feeling that the patient was taking responsibility for their health, perceiving the request as appropriate, and doing what the patient wanted. ${ }^{4}$ In a different study, improved advanced practice nurse prescriber-patient relationship was associated with factors, such as the patient not bringing printed material during the visit, not seeking a referral, seeking nurse's opinion only, not challenging nurses' authority, and taking responsibility for their health, as was with the nurse having enough time to discuss the information. ${ }^{10}$ It was hypothesized that:

\section{H1: DTCA information discussed during an office visit may be associated with the provider-patient relationship.}

Delbaere and Smith proposed that consumers who have no knowledge of prescription drugs learn from DTCA differently than those who have.12 Further, consumers process DTCA information differently depending on their perceptions of the effectiveness of advertisements. ${ }^{12}$ Moreover, consumers use what they learn from the advertisements in many different ways, some of which may be found inappropriate or irrational by health care providers, and challenge the providers' prescriptive authority and expertise. ${ }^{12}$ Specifically, an intervention that was not clinically indicated, not doing what the patient wanted, and not knowing the patient well enough to have good communication were factors associated with the doctors more likely to feel their prescriptive authority had been challenged as well as with worsened time efficiency of the visit. ${ }^{4}$ Similar factors were found to be associated with advanced practice nurse prescribers' challenged prescriptive authority, namely: the nurse not having enough time to discuss the information, knowing the patient well enough to have a good communication, believing that the increase in drug advertisements was a very bad thing, and the patient not taking responsibility for their health. ${ }^{10}$ Hence, it was hypothesized that:

H2: DTCA information discussed during an office visit may be associated with provider's prescriptive authority being challenged. H3: DTCA information discussed during an office visit may be associated with the time efficiency of the visit.

Research on the benefits and drawbacks of DTCA has been limited and mostly based on studies involving physicians. $4,5,7$ Few studies have also explored the specific effects of DTCA information discussed during patient encounters. 4,10 The purpose of the study was to examine physician assistants' general views of DTCA benefits and drawbacks. It is also the first study to test the effects of DTCA information discussed during patient encounters on physician assistant-patient relationship, physician assistants' prescriptive authority and time efficiency of the visit. DTCA has continued to grow over the years and has the potential to influence providers, including physicians, physician assistants, and nurse practitioners. Hence, it is important to examine data reflective of diverse provider practices and experiences to inform the ongoing policy debate and research surrounding DTCA.

\section{METHODS}

\section{Sampling and Data Collection}

This study uses a cross-sectional survey design. The target population for this study consists of PAs who hold a current license in the state. Data on the names and addresses of PAs were obtained from the Department of Safety and Professional Services. A sample of 860 participants was drawn from the population of 4,483 physician assistants (confidence interval [Cl]: $95 \%$; margin of error: $\pm 2.7,50 \%$ confidence). Of the 860 surveys that were delivered, 136 were returned by mail and 39 were completed online for a total of $175(20.35 \%)$. Fourteen surveys were excluded from data analysis for the following reasons: declined to participate, incomplete or the PAs had either retired, or no longer practiced as PAs. The final study sample consisted of 161 participants for a usable response rate of $18.72 \%$. Of these, 149 PAs had experience with DTCA discussion with a patient during an office visit during the last 12 months. 
The study was approved by the Institutional Review Board at the investigator's university. A mixed mode of mail and online data collection approach was used. ${ }^{13}$ The data collection procedures include: 1) sending a pre-notice letter, 2) mailing a cover letter/survey a week later, 3) following up with a reminder postcard one week after mailing survey, and 4) following up with a reminder card two weeks after the mailing of the first postcard. In the cover letter, PAs were assured complete anonymity; that participation was voluntary; that they could also complete the survey online, using the Qualtrics system; and that they might request an executive summary of the study.

\section{Instruments and Measures}

Likert-type questions ( 1 = Strongly Disagree; 5 = Strongly Agree) regarding DTCA benefits and drawbacks were adopted from a previously tested instrument and the literature review. $4,7,10$ The instrument was assumed to have content validity and reliability. ${ }^{7}$ In addition, questions were adopted from previous research to test the relationships between the dependent and independent variables. ${ }^{4,10}$ The independent variables, measured with closed-ended questions (1=Yes; 2=No), included whether the patient brought a printed advertisement material; the reason the patient talked to the PA in relation to the advertisement: wanted a test, wanted a particular drug, wanted a referral to specialist, wanted PA's opinion only, wanted a prescription drug change; whether the PA did what the patient wanted; whether the PA felt the patient's request was inappropriate for their health; whether the PA felt the patient was challenging his/her prescriptive authority/expertise; whether the patient was taking responsibility for their health; and whether the PA did not know the patient well enough to have a good communication. Additional independent variables were measured on a Likert scale ( $1=$ Not at All; $5=$ To a Great Extent) and included whether the DTCA information was relevant to the patient's disease; whether the DTCA information was accurate enough; and the extent to which the PA met this patient's information needs. The dependent variables used in this particular study included: PAs' views of whether the patient bringing DTCA information to a visit affected the physician assistant-patient relationship ( $1=$ Worsened Much; $5=1 \mathrm{mproved}$ Much); PAs' views of whether the patient bringing DTCA information to a visit affected the time efficiency of the visit ( $1=$ Worsened Much; $5=$ Improved Much); and PAs' feelings of whether their prescriptive authority/expertise has been challenged ( $1=\mathrm{Yes} ; 2=\mathrm{No})$. The survey also collected data on PAs' demographic and practice-related characteristics.

\section{Statistical Analyses}

Descriptive statistics analysis (frequencies) was carried out, using Stata/IC 12.1 of StataCorp LP of all variables. Pearson's chisquared analysis, logistic regression and multinomial logistic regression analyses were used to measure the associations between the dependent and independent variables. Prior to analysis, those variables were recoded 0, 1 (No/Yes respectively), while the Likert-scale categories were collapsed to three. For the binary independent variables, the odds ratios and percentage change in odds were interpreted directly. For independent variables that were not binary, the odds ratio for a 1 -standard-deviation change in the predictor and percentage change in odds were used. ${ }^{14}$

The associations between dependent variables 'PA-patient relationship' and 'time efficiency of the visit' and the independent variables were investigated using multinomial logistic regression. Multinomial logistics regression coefficients and $95 \%$ confidence intervals were reported. Since the parameter estimates are relative to the referent group (improved/improved much), the standard interpretation of the multinomial logit is that for a unit change in the independent variable, the logit of an outcome relative to the referent group is expected to change by its respective parameter estimate given the variables in the model are held constant. ${ }^{15}$ The relative risk ratio (RRR) coefficients were also reported. These indicate how the risk of the outcome falling in the comparison group compared to the risk of the outcome falling in the referent group changes with the variable in question. ${ }^{13}$ Diagnostic tests were conducted to assess for multicollinearity, specification errors, influential observations, and model specification. Diagnostic analysis showed no violation of the logistic regression assumptions. For the multinomial logistic regression models, model fit statistics was performed and was satisfactory.

\section{RESULTS}

\section{Participants' Demographic and Practice Characteristics}

Table 1 presented descriptive statistics of participants' demographic and practice characteristics. The 161 PAs were predominantly white (81\%), female $(71 \%)$, and $31 \%$ were between the ages of $20-39$. Twenty-seven percent of PAs had more than 20 years of practice as a PA. The respondents had the following job specialties: family/general practice (37\%), general surgery (3\%), internal medicine $(10 \%)$, emergency medicine $(14 \%)$, pediatrics $(3 \%)$ and other specialties $(34 \%)$. More than half of the PAs practiced predominantly in clinics (58\%). Forty-four percent of PAs reported seeing between 40-59 patients per week and spent between 17-24 minutes per patient (55\%). 
Table 1. Demographic and Practice Characteristics of Respondents $(N=161)$

\begin{tabular}{|c|c|}
\hline & $N(\%)$ \\
\hline \multicolumn{2}{|l|}{ Gender } \\
\hline Men & $23.60(38)$ \\
\hline Women & $70.81(114)$ \\
\hline Other & $5.59(9)$ \\
\hline \multicolumn{2}{|l|}{ Age Group } \\
\hline$<20$ & $2.48(4)$ \\
\hline $20-39$ & $31.06(50)$ \\
\hline $40-49$ & $17.39(28)$ \\
\hline $50-59$ & $21.74(35)$ \\
\hline 60> & $27.33(44)$ \\
\hline \multicolumn{2}{|l|}{ Ethnicity/Race } \\
\hline White & $81.37(131)$ \\
\hline African American & $5.59(9)$ \\
\hline Hispanic & $6.21(10)$ \\
\hline Asian American/Pacific Islander & $3.73(6)$ \\
\hline American Indian & $1.24(2)$ \\
\hline Other Race & $1.86(3)$ \\
\hline \multicolumn{2}{|c|}{ Years of Practice as Physician Assistant } \\
\hline$<1$ & $5.59(9)$ \\
\hline $1-4$ & $18.01(29)$ \\
\hline $5-9$ & $13.66(22)$ \\
\hline $10-14$ & $26.09(42)$ \\
\hline $15-19$ & $9.32(15)$ \\
\hline $20>$ & $27.33(44)$ \\
\hline \multicolumn{2}{|l|}{ Specialty } \\
\hline Family/General & $37.27(60)$ \\
\hline General Surgery & $3.11(5)$ \\
\hline Internal Medicine & $9.94(16)$ \\
\hline Emergency Medicine & $13.66(22)$ \\
\hline Pediatrics & $2.48(4)$ \\
\hline Other & $33.54(54)$ \\
\hline \multicolumn{2}{|l|}{ Setting } \\
\hline Clinic & $57.76(93)$ \\
\hline Hospital & $27.33(44)$ \\
\hline Physician Office & $7.45(12)$ \\
\hline Long-term Care & $3.11(5)$ \\
\hline Correction Institution & $1.86(3)$ \\
\hline Other & $2.48(4)$ \\
\hline \multicolumn{2}{|c|}{ Number of Patients Seen Per Week } \\
\hline$<20$ & $6.83(11)$ \\
\hline $20-29$ & $7.45(12)$ \\
\hline $30-39$ & $13.66(22)$ \\
\hline $40-49$ & $26.09(42)$ \\
\hline $50-59$ & $18.01(29)$ \\
\hline $60>$ & $27.95(45)$ \\
\hline \multicolumn{2}{|l|}{ Minutes Spent with Each Patient } \\
\hline$<9$ & $2.48(4)$ \\
\hline $10-12$ & $11.18(18)$ \\
\hline $13-16$ & $18.63(30)$ \\
\hline $17-20$ & $36.02(58)$ \\
\hline $21-24$ & $18.63(30)$ \\
\hline
\end{tabular}


25>

$13.04(21)$

Perceptions of DTCA Benefits and Drawbacks

The descriptive statistics in Table 2 indicated that of all respondents $(N=161)$, most PAs thought that DTCA drove up the costs of prescription drugs $76 \%(95 \% \mathrm{Cl}, 73.3$ to $78.7 \%)$, promoted unnecessary fear of side effects $71 \%(95 \% \mathrm{Cl}, 68.3$ to $73.7 \%)$, did not provide a balanced view of risks and benefits $64 \%(95 \% \mathrm{Cl}, 61.3$ to $66.7 \%)$, did not promote PA-supervising physician communication $52 \%$ (95\% Cl, 49.3 to $54.7 \%)$, and often mislead patients $53 \%(95 \% \mathrm{Cl}, 50.3$ to $55.7 \%)$. On the other hand, most PAs agreed that DTCA alerted patients to new therapies $(74 \%, 95 \% \mathrm{Cl}, 71.3$ to $76.7 \%)$ and did not create a conflict between the PA and the supervising physician $71 \%(95 \% \mathrm{Cl}, 68.3$ to $73.7 \%)$. PAs were divided on issues, such as DTCA promoting PA-patient communication and giving patients confidence to talk to their PA.

Table 2. Physician Assistant Views of the Effects of Direct-to-Consumer Advertising ( $N=161)$

\begin{tabular}{|l|l|l|l|}
\hline Direct-to-Consumer Drug Advertising: & $\begin{array}{l}\text { Disagree/Strongly } \\
\text { Disagree } \\
\%(\mathrm{n})\end{array}$ & $\begin{array}{l}\text { Neutral } \\
\%(\mathrm{n})\end{array}$ & $\begin{array}{l}\text { Agree/Strongly } \\
\text { Agree } \\
\%(\mathrm{n})\end{array}$ \\
\hline 1. drives up the costs of prescription drugs & $10.56(17)$ & $13.04(21)$ & $76.40(123)$ \\
\hline $\begin{array}{l}\text { 2. gives patients confidence to talk to their PA about their } \\
\text { concerns }\end{array}$ & $17.39(28)$ & $40.37(65)$ & $42.24(68)$ \\
\hline $\begin{array}{l}\text { 3. interferes with good relationships between PAs and } \\
\text { patients }\end{array}$ & $32.92(53)$ & $37.89(61)$ & $29.19(47)$ \\
\hline 4. promotes unnecessary visits to the PA's office & $36.02(58)$ & $37.27(60)$ & $26.71(43)$ \\
\hline $\begin{array}{l}\text { 5. encourages patients to follow treatment instructions or } \\
\text { advice from their PA }\end{array}$ & $27.95(45)$ & $44.1(71)$ & $27.95(45)$ \\
\hline 6. causes patients to take up more of their PA's time & $21.74(35)$ & $30.43(49)$ & $47.83(77)$ \\
\hline $\begin{array}{l}\text { 7. improves patients' understanding of medical conditions } \\
\text { and treatments }\end{array}$ & $39.75(64)$ & $28.57(46)$ & $31.68(51)$ \\
\hline 8. promotes unnecessary fear of side effects & $16.15(26)$ & $12.42(20)$ & $71.43(115)$ \\
\hline $\begin{array}{l}\text { 9. helps patients get treatments they would not otherwise } \\
\text { get }\end{array}$ & $44.10(71)$ & $24.84(40)$ & $31.06(50)$ \\
\hline 10. discourages the use of generic products & $28.57(46)$ & $21.74(35)$ & $49.69(80)$ \\
\hline 11. alerts patients to new therapies & $6.21(10)$ & $19.88(32)$ & $73.91(119)$ \\
\hline $\begin{array}{l}\text { 12. pressures PAs to prescribe drugs they might not } \\
\text { ordinarily prescribe }\end{array}$ & $39.75(64)$ & $25.47(41)$ & $34.78(56)$ \\
\hline 13. often misleads patients & $19.25(31)$ & $23.60(38)$ & $57.14(92)$ \\
\hline 14. promotes PA-patient communication & $21.74(35)$ & $39.13(63)$ & $39.13(63)$ \\
\hline $\begin{array}{l}\text { 15. promotes compliance with patient's treatment } \\
\text { regimens }\end{array}$ & $38.51(62)$ & $37.27(60)$ & $24.22(39)$ \\
\hline $\begin{array}{l}\text { 16. presents a balanced view of risks and benefits of the } \\
\text { product }\end{array}$ & $63.98(103)$ & $27.33(44)$ & $8.70(14)$ \\
\hline 17. bias patients in favor of physicians over PAs & $48.45(78)$ & $40.99(66)$ & $10.56(17)$ \\
\hline 18. should have stricter regulation & $29.81(48)$ & $25.47(41)$ & $44.72(72)$ \\
\hline 19. promotes PA-supervising physician communication & $51.55(83)$ & $38.51(62)$ & $9.94(16)$ \\
\hline $\begin{array}{l}\text { 20. creates a conflict between PA and supervising } \\
\text { physician }\end{array}$ & $71.43(115)$ & $22.36(36)$ & $6.21(10)$ \\
\hline
\end{tabular}

\section{Perceptions about DTCA Information Discussed in a Visit}

Respondents were asked about the last time a patient talked about information from a drug advertisement during a visit. Of the 161 participants, 149 had experienced patients bringing information from DTCA to a visit in the previous 12 months or $92.6 \%$ of respondents. Patients did so because they wanted a particular drug $(49 \%, 95 \% \mathrm{Cl}, 46.3$ to $51.7 \%)$. However, $62 \%$ of PAs $(95 \%$ $\mathrm{Cl}, 59.3$ to $64.7 \%$ ) deemed patient's request inappropriate. Most PAs reported that they did not do what the patient wanted; that they did have enough time to discuss the information; that they felt the patient was taking responsibility for their health; that the patient was not challenging their authority; that they knew the patient well enough to have good communication; that the patient's request for clinical intervention was not appropriate; and that they met the patient's information needs (see Table 2). Further, drug advertisements brought by the patient were reported as somewhat accurate and relevant. 


\section{Effect of DTCA Information Discussed on Provider-Patient Relationship}

Table 3 in the Appendices showed that most PAs $(74 \%, 95 \% \mathrm{Cl}, 71.3$ to $76.7 \%)$ thought that patients bringing in information from a drug advertisement did not change the PA-patient relationship; $21 \%(95 \% \mathrm{Cl}, 18.3$ to $23.7 \%)$ thought that relationship 'improved/improved much;' and 5\% $(95 \% \mathrm{Cl}, 2.3$ to $7.7 \%)$ thought that it 'worsened/worsened much." The Pearson's chi-squared analysis revealed that an 'improved/improved much' PA-patient relationship was more likely to be associated with the patient wanting a referral, the PA doing what the patient wanted, the patient taking responsibility for their health, the drug advertisement information being accurate, and the PA meeting patient's information needs. Conversely, the patient challenging the PA's prescriptive authority was associated with a deterioration of the relationship.

The analysis of multinomial logistic regression showed that the relative risk for 'no change' in PA-patient relationship to an "improved/improved much" one would be expected to decrease when the patient wanted a particular drug (RRR 0.16; $\mathrm{Cl}, 0.0$ to 0.8 ), the patient wanted a referral (RRR $0.21 ; \mathrm{Cl}, 0.1$ to 0.9 ), the PA doing what the patient wanted (RRR $0.07 ; \mathrm{Cl}, 0.0$ to 0.3 ), and the patient challenging the PA's prescriptive authority (RRR $0.14 ; \mathrm{Cl}, 0.0$ to 0.8 ). The relative risk for "no change" in PA-patient relationship to an "improved/improved much" one would be expected to increase if the PA knew the patient well enough to have good communication (RRR 5.90; $\mathrm{Cl}, 1.2$ to 28.1). The multinomial logistic regression model was statistically significant (Pseudo Rsquared $.4326, p<.001)$.

\section{Effect of DTCA Information Discussed on Prescriptive Authority}

Only $12 \%(95 \% \mathrm{Cl}, 9.35$ to $14.7 \%)$ of the PAs felt that their authority had been challenged by the patient during the discussion DTCA information. The chi-squared analysis revealed that PAs were more likely to feel their authority had been challenged with the patient bringing a printed advertisement material $\left(26 \%\right.$ vs. $101 \% ; \chi^{2}(1, N=149)=4.15 ; p<.05$; Cramér's $\left.V=0.17\right)$; the patient wanting a particular drug $\left(18 \%\right.$ vs. $7 \% ; \chi^{2}(1, N=149)=4.42 ; p<.05 ;$ Cramér's $\left.V=0.17\right)$, and when the relationship between the $\mathrm{PA}$ and the patient worsened/worsened much $\left(57 \%\right.$ vs. $7 \%$ vs. $19 \% ; \chi^{2}(2, N=149)=14.77 ; p<.001$; Cramér's $\left.V=0.32\right)$. Conversely, PAs were more likely to feel their authority had not been challenged when the PAs had enough time to discuss the DTCA information ( $92 \%$ vs. $74 \% ; \chi^{2}(1, N=149)=8.01 ; p<.01$; Cramér's $\left.V=0.23\right)$. The multinomial logistic regression model was not statistically significant.

\section{Effect of DTCA Information Discussed on the Time Efficiency of Visit}

Table 4 in the Appendices showed that more PAs viewed discussing information from a drug advertisement as worsening the time efficiency of the visit $(74 \% ; 95 \% \mathrm{Cl}, 71.3$ to $76.7 \%)$, whereas $26 \%$ reported "no change" ( $95 \% \mathrm{Cl}, 23.3$ to $28.7 \%)$. No respondents reported an "improved" or "improved much" efficiency.

Pearson's chi-squared analysis revealed that worsened time efficiency was more likely to occur with the patient bringing a printed advertisement material (95\% vs. $710 \% ; \chi^{2}(1, N=149)=4.93 ; p<.05$; Cramér's $\left.V=0.18\right)$, the patient wanting a test $(89 \%$ vs. $70 \% ; \chi^{2}(1, N=149)=4.27 ; p<.05$; Cramér's $\left.V=0.17\right)$, and the advertisement not being relevant to the patient's medical condition $\left(88 \%\right.$ vs. $80 \%$ vs. $50 ; \chi^{2}(2, N=149)=15.69 ; p<.001 ;$ Cramér's $\left.V=0.33\right)$.

The analysis of multinomial logistic regression showed that the relative risk for "worsened/worsened much" time efficiency of the visit to "no change" in the efficiency would be expected to decrease when the advertisement information was relevant to the medical condition of the patient (RRR $0.45 ; \mathrm{Cl}, 0.2$ to 0.9 ). Conversely, the relative risk for "worsened/worsened much" time efficiency of the visit to "no change" in the efficiency would be expected to increase when the patient wanted a test (RRR 5.37; $\mathrm{Cl}, 1.1$ to 25.8). The multinomial logistic regression model was statistically significant (Pseudo R-squared .2133, $p<.01$ ).

\section{CONCLUSIONS, RECOMMENDATIONS AND LIMITATIONS}

There has been a lack of empirical studies on how DTCA information discussed during an office visit affects PA's practice and relationship with patients. ${ }^{4,10}$ Within the physician-PA relationship, PAs exercise autonomy in making decisions about patient treatment and provide a broad range of services, including writing prescriptions. This study found that $93 \%$ of PAs were likely to encounter patients who sought information as a result of DTCA, and that DTCA gave patients confidence to talk to their PAs about their concerns (42\%) and promoted PA-patient communication (39\%). On the other hand, increased prescription drug costs, promoting fear of side effects and misleading patients were some of the most commonly reported drawbacks of DTCA.

The study also provided preliminary evidence that improved PA-patient relationship was more likely to occur when PAs did what patients wanted; when patients were taking responsibility for their health; when the DTCA information discussed was accurate; when PAs met patients' information needs; and when PAs knew the patient well enough to have good communication. PAs were more likely to feel their prescriptive authority had been challenged when patients brought DTCA info to the visit; wanted a particular 
drug, and when the PA-patient relationship had worsened. These findings were consistent with previous empirical studies.4,10 Consistent with the findings of Murray et al, worsened time efficiency of the visit was more likely to occur with the patient bringing a printed advertisement material, the patient wanting a test, and the DTCA drug information not being relevant to the patient's medical condition. ${ }^{4}$ Hooker et al determined that the total costs of a visit or the cost of an episode of an illness was more economical overall when the PA delivered similar care to that of the physician. ${ }^{16}$ This suggests that DTCA may negatively affect employers in terms of PAs taking more time to explain contradictory drug information or patients' requests for unnecessary treatment options or drugs.

\section{Recommendations}

Overall, PAs had mixed feelings of DTCA benefits and risks, which was in line with prior research.1-9 The findings imply that PA input should be sought in the development of DTCA guidelines and legislation, because these providers are affected by DTCA.

The findings also imply that PAs need enhanced awareness of DTCA information discussion effects during patient encounters. Emotional intelligence training could facilitate PAs to better understand their emotional responses to patients and how their emotions impact their prescribing, diagnostic actions and clinical decision-making. ${ }^{17,18}$ Arora et al. found that higher emotional intelligence was positively associated with doctor-patient relationship, increased empathy, teamwork and communication skills. ${ }^{18}$ PAs can also take advantage of "self-awareness spiral curriculum," which has been used for developing physician emotional intelligence competencies beyond the period of formal medical training. ${ }^{17}$ The spiral curriculum (self as a student; self as a member of the healthcare team; self as a doctor; and self as a teacher and leader) could be used for training and developing emotional intelligence competencies over time and address physician's situational needs. ${ }^{17}$ This developmental approach implied the need for ongoing training and leadership developing beyond the period of formal medical training. ${ }^{17}$ Similar types of self-awareness training could be provided to PAs to meet their situational needs. Such training would allow them to gain insight about their emotional responses to patients who approach them about DTCA information and may reduce PAs feelings of their prescriptive authority/expertise being challenged.

PAs also need to have the skills and training to effectively communicate DTCA information and negotiate appropriate treatment options. Parker et al. suggest that any communication skills training should be specific to the areas that PAs might find challenging to their specialty. ${ }^{19}$ When it comes to DTCA encounters, such training could involve both the PA and the supervising physician and focus, for example, on how to collaboratively devise a care plan that meets patients' goals and expectations; how to explain conflicted/unclear drug information; how to negotiate appropriate treatment options and encourage patient compliance; how to discuss prescribing decisions and clinical interventions to minimize feelings of being pressured; and how to use DTCA information as a health promotion and educational tool. An external assessment of communication skills by trained peers was suggested as a first step in improving the standard of provider-patient communication..$^{20}$

Greater collaboration and communication between the PAs and their supervising physician about DTCA encounters cannot be understated. In this study, $52 \%$ of PAs noted that DTCA did not promote PA-supervising physician communication, but that it also did not create a conflict with the supervising physician $(71 \%)$. These findings suggest the importance of the PA maintaining coordinated consultation with their supervising physician about specific DTCA requests made by the patient. Chuang et al. also found that PAs were able to communicate best when they had support from their supervising physicians and specialists, as well as a shared understanding about the patient treatment options. ${ }^{21}$ The results regarding worsened time efficiency of the visit may suggest that employers should consider training that teaches PAs how to navigate DTCA discussion during a visit to minimize the costs of an episode of an illness. ${ }^{16}$

\section{Limitations}

This study has a few limitations. First, as a cross-sectional study, causation cannot be ascertained. Second, despite efforts to increase the survey response rate by providing an opportunity for mailed and online survey completion and multiple mailings, the response rate was low and might suggest a response bias. It is possible that the PAs might have self-selected themselves based on experience or interest in the study; so, the findings might not be generalizable. ${ }^{11}$ The analysis of demographic and practicerelated characteristics, however, revealed that the sample studied was very similar to the 2017 AAPA census by specialty, practice, age, and geographic distribution. ${ }^{22}$ Third, the results were also collected from a single state. Although PAs' participation in this study was evenly present from all regions of the state (Northeastern 23\%; Northern 27\%; Southeastern 19\%; Southern 18\%; Western 14\%), generalization to other states is limited as PAs' views might differ across markets.

\section{CONCLUSIONS}

This study extended prior research on PAs' views of the DTCA benefits and drawbacks. ${ }^{9}$ It was also the first to report DTCA effects on the PA-patient relationship, prescriptive authority, and time efficiency of the visit. Findings showed that PAs viewed DTCA as 
having both positive and negative effects on the patient, provider, and the health care system. To enhance the PA-patient relationship and the time efficiency of the visit, it may be important to enhance dialogue between the PAs and their supervising physicians about patient needs and provide targeted training that sharpens PAs' communication, interpersonal skills, and emotional intelligence skills during DTCA encounters. It is also important to incorporate PAs' perspectives in the development of guidelines governing DTCA. Future research should replicate this study on a national level and also incorporate qualitative questions that solicit information of PA training and developmental needs to better handle DTCA requests.

\section{REFERENCES}

1. Ventola LC. Direct-to-consumer pharmaceutical advertising: therapeutic or toxic? Pharm Ther. 2011; 36(10):669-684. [PMID 22346300]

2. Celia F. Pharma ups the ante on DTCA. Pharmaceutical Commerce.

https://pharmaceuticalcommerce.com/brand-marketing-communications/pharma-ups-ante-dtc-advertising/ Published Apr 4, 2017. Accessed April 1, 2019.

3. Applequist J, Ball J G. An updated analysis of direct-to-consumer television advertisements for prescription drugs. Ann Fam Med. 2018; 16(3): 211-216. [PMID 29760024]

4. Murray E, Lo B, Pollack L, Donelan K, Lee K. Direct-to-consumer advertising: physicians' views of its effects on quality of care and the doctor-patient relationship. JABMF 2003; 16(6):513-524. [PMID 14963078]

5. U.S. Food and Drug Administration. Patient and physician attitudes and behaviors associated with DTC promotion of prescription drugs: summary of FDA survey research results.

https://www.fda.gov/downloads/AboutFDA/CentersOffices/OfficeofMedicalProductsandTOffice/CDER/UCM600276.pdf. Accessed January 23, 2019.

6. Arney J, Lewin, B. Models of physician-patient relationships in pharmaceutical direct-to-consumer advertising and consumer interviews. Qualitative Health Research. 2013; 23(7): 937-950. [PMID 23645149]

7. Lipsky, MS, Taylor CA. The opinions and experiences of family physicians regarding direct-to-consumer advertising. J Fam Pract. 1997; 45:495-499. [PMID 9420585]

8. Raleign BM. Nurse practitioners and direct-to-consumer drug advertising. Master's Thesis, Gonzaga University, Spokane, WA, 2002.

9. Anzalone J, Mathews A, Suprenant M, Herman L. Perceptions of physician assistants regarding direct-to-consumer advertising. JAAPA 2012; 25(2):56. [PMID 22416556]

10. Author, 2018 [PMID]

11. Young HN, Lipowski, EE, Cline, RJW. Using social cognitive theory to explain consumers' behavioral intentions in response

to direct-to-consumer prescription drug advertising. Res Soc Adm Pharm 2005; 1:270-288. [PMID 17138478]

12. Delbaere M, and Smith MC. Health care knowledge and consumer learning: the case of direct-to-consumer advertising.

Health Mark Q 2006; 23(3): 9-29. [PMID 18681197]

13. Dillman D.A. Smyth J.D. Christian L. M. Internet, mail and mix-mode surveys: the tailored design method. 4th ed. Hoboken,

NJ: John Wiley \& Sons; 2014

14. Acock AC. Gentle introduction to Stata. $3^{\text {rd }}$ ed. College Station, TX: Stata Press; 2012.

15.Stata annotated output: multinomial logistic regression. UCLA: Statistical Consulting Group.

https://stats.idre.ucla.edu/stata/output/multinomial-logistic-regression/. Accessed Jan. 14, 2019.

16. Hooker RS, Everett CM. The contributions of physician assistants in primary care systems. Health Soc Care Community. 2012; 20(1): 20-31. [PMID 21851446]

17. Stoller JK, Taylor CA, Farver CF. Emotional intelligence competencies provide a developmental curriculum for medical training. Med Teacher. 2013; 35(3): 243-247. [PMID 23360483]

18. Arora S, Ashrafian H, Davis R, et al. Emotional intelligence in medicine: a systematic review through the context of the ACGME competencies. Med Edu. 2010; 44(8): 749-764. [PMID 20633215]

19. Parker PA, Ross AC, Polansky MN, et al. Communicating with cancer patients: what areas do physician assistants find most challenging? J Canc Edu. 2010; 25:524-529. [PMID 20383673]

20. Burt J, Abel G, Elliot MN, Elmore N. et al. The evaluation of physicians' communication skills from multiple perspectives. Ann Fam Med. 2018; 16(4): 330-337. [PMID 29987081]

21. Chuang E, Lamkin R, Hope AA, et al. "I just felt like I was stuck in the middle": physician assistants' experiences

communicating with terminally ill patients and their families in the acute care setting. J Pain \& Symptom Mgmt. 2017; 54(1):27-

34. [PMID 28479409]

22. American Academy of PAs. PA workforce 2017: an update. https://paeaonline.org/wp-content/uploads/2017/12/PA-

Workforce-2017-An-Update.pdf. Accessed Jan. 7, 2019 
APPENDICES

(C) The Internet Journal of Allied Health Sciences and Practice, 2020 
Table 3. Factors Affecting Physician Assistant-Patient Relationship during Discussion about DTCA ( $N=149)$

\begin{tabular}{|c|c|c|c|c|c|c|c|c|c|}
\hline \multirow[t]{5}{*}{ Independent Variables } & \multirow[b]{5}{*}{$\%(n)$} & \multicolumn{8}{|c|}{ Dependent Variable: Physician Assistant-Patient Relationship } \\
\hline & & \multirow{3}{*}{\multicolumn{4}{|c|}{ Pearson's Chi-Square }} & \multirow{2}{*}{\multicolumn{4}{|c|}{$\begin{array}{l}\text { Multinomial Logistic Regression } \\
\text { LR chi2(30): } 90.97^{* * *} ; \text { Pseudo R2: } 0.4326 \\
\text { IMP (Reference Group) }\end{array}$}} \\
\hline & & & & & & & & & \\
\hline & & & & & & \multicolumn{2}{|c|}{$\mathbf{W}$} & \multicolumn{2}{|c|}{ NC } \\
\hline & & $\begin{array}{c}\%(n) \\
5.4(8) \\
W\end{array}$ & $\begin{array}{c}\%(n) \\
73.8(110) \\
\text { NC }\end{array}$ & $\begin{array}{c}\%(n) \\
20.8(31) \\
\text { IMP }\end{array}$ & $\begin{array}{c}X^{2}(\mathrm{df}) p \\
V\end{array}$ & $\begin{array}{c}\text { Coef } \\
(95 \% \mathrm{Cl})\end{array}$ & $\begin{array}{c}\text { RRR } \\
(95 \% \mathrm{Cl})\end{array}$ & $\begin{array}{c}\text { Coef } \\
(95 \% \mathrm{Cl})\end{array}$ & $\begin{array}{c}\text { RRR } \\
(95 \% \mathrm{Cl})\end{array}$ \\
\hline $\begin{array}{c}\text { Did the patient bring printed ad material? } \\
\text { Yes } \\
\text { No }\end{array}$ & $\begin{array}{c}12.8(19) \\
87.3(130)\end{array}$ & $\begin{array}{c}10.53 \\
4.62\end{array}$ & $\begin{array}{l}57.89 \\
76.15\end{array}$ & $\begin{array}{l}31.58 \\
19.23\end{array}$ & $\begin{array}{c}3.04(2) \\
0.14\end{array}$ & 1.62 & 5.07 & -0.84 & 0.43 \\
\hline $\begin{array}{r}\text { Did the patient want a test? } \\
\text { Yes } \\
\text { No }\end{array}$ & $\begin{array}{c}18.8(28) \\
81.2(121)\end{array}$ & $\begin{array}{c}10.71 \\
4.13\end{array}$ & $\begin{array}{l}71.43 \\
74.38\end{array}$ & $\begin{array}{l}17.86 \\
21.49\end{array}$ & $\begin{array}{c}2.0(2) \\
0.12\end{array}$ & 0.52 & 1.68 & 1.04 & 2.83 \\
\hline $\begin{array}{c}\text { Did the patient want a particular drug? } \\
\text { Yes } \\
\text { No }\end{array}$ & $\begin{array}{l}48.99(73) \\
51.01(76)\end{array}$ & $\begin{array}{l}5.48 \\
5.26\end{array}$ & $\begin{array}{l}68.49 \\
78.95\end{array}$ & $\begin{array}{l}26.03 \\
15.79\end{array}$ & $\begin{array}{c}2.4(2) \\
0.13\end{array}$ & -18.02 & 1.49 & $\begin{array}{c}-1.86^{*} \\
(-3.4--0.3)\end{array}$ & $\begin{array}{c}0.16 \\
(0.0-0.8)\end{array}$ \\
\hline $\begin{array}{l}\text { Did the patient want a referral? } \\
\qquad \text { Yes } \\
\text { No } \\
\end{array}$ & $\begin{array}{c}14.8(22) \\
85.2(127) \\
\end{array}$ & $\begin{array}{c}18.18 \\
3.15 \\
\end{array}$ & $\begin{array}{l}50.00 \\
77.95 \\
\end{array}$ & $\begin{array}{l}31.82 \\
18.90 \\
\end{array}$ & $\begin{array}{c}11.38(2)^{* *} \\
0.28\end{array}$ & 17.62 & 4.51 & $\begin{array}{c}-1.55^{*} \\
(-3.0--0.1)\end{array}$ & $\begin{array}{c}0.21 \\
(0.1-0.9)\end{array}$ \\
\hline $\begin{array}{c}\text { Did the patient want a drug change? } \\
\text { Yes } \\
\text { No }\end{array}$ & $\begin{array}{c}14.8(22) \\
85.2(127)\end{array}$ & $\begin{array}{l}0.00 \\
6.30\end{array}$ & $\begin{array}{l}63.64 \\
75.59 \\
\end{array}$ & $\begin{array}{l}36.36 \\
18.11 \\
\end{array}$ & $\begin{array}{c}4.76(2) \\
0.18\end{array}$ & -17.53 & 2.43 & -1.27 & 0.28 \\
\hline $\begin{array}{l}\text { Did the patient want your opinion only? } \\
\text { Yes } \\
\text { No }\end{array}$ & $\begin{array}{l}55.03(82) \\
44.97(67)\end{array}$ & $\begin{array}{l}6.10 \\
4.48\end{array}$ & $\begin{array}{l}76.83 \\
70.15\end{array}$ & $\begin{array}{l}17.07 \\
25.37\end{array}$ & $\begin{array}{c}1.62(2) \\
0.10\end{array}$ & 0.75 & 2.12 & -0.30 & 0.74 \\
\hline $\begin{array}{l}\text { Did you do what the patient wanted? } \\
\text { Yes } \\
\text { No }\end{array}$ & $\begin{array}{l}40.9(61) \\
59.1(88)\end{array}$ & $\begin{array}{l}6.56 \\
4.55\end{array}$ & $\begin{array}{l}59.02 \\
84.09\end{array}$ & $\begin{array}{l}34.43 \\
11.36\end{array}$ & $\begin{array}{c}12.55(2)^{* *} \\
0.29\end{array}$ & 20.79 & 1.06 & $\begin{array}{c}-2.72^{* * *} \\
(-4.3--1.1)\end{array}$ & $\begin{array}{c}0.07 \\
(0.0-0.3)\end{array}$ \\
\hline $\begin{array}{l}\text { Did you have enough time to discuss the ad } \\
\text { information? } \\
\qquad \begin{array}{l}\text { Yes } \\
\text { No }\end{array}\end{array}$ & $\begin{array}{c}76.5(114) \\
23.5(35)\end{array}$ & $\begin{array}{l}4.39 \\
8.57 \\
\end{array}$ & $\begin{array}{l}71.93 \\
80.00\end{array}$ & $\begin{array}{l}23.68 \\
11.43 \\
\end{array}$ & $\begin{array}{c}3.04(2) \\
0.14\end{array}$ & 19.54 & 3.07 & -0.86 & 0.42 \\
\hline $\begin{array}{l}\text { Did you feel the patient was taking } \\
\text { responsibility for their health? } \\
\text { Yes }\end{array}$ & $83.2(124)$ & 6.45 & 69.35 & 24.19 & $7.69(2)^{*}$ & 39.56 & 1.52 & -2.20 & 0.11 \\
\hline
\end{tabular}




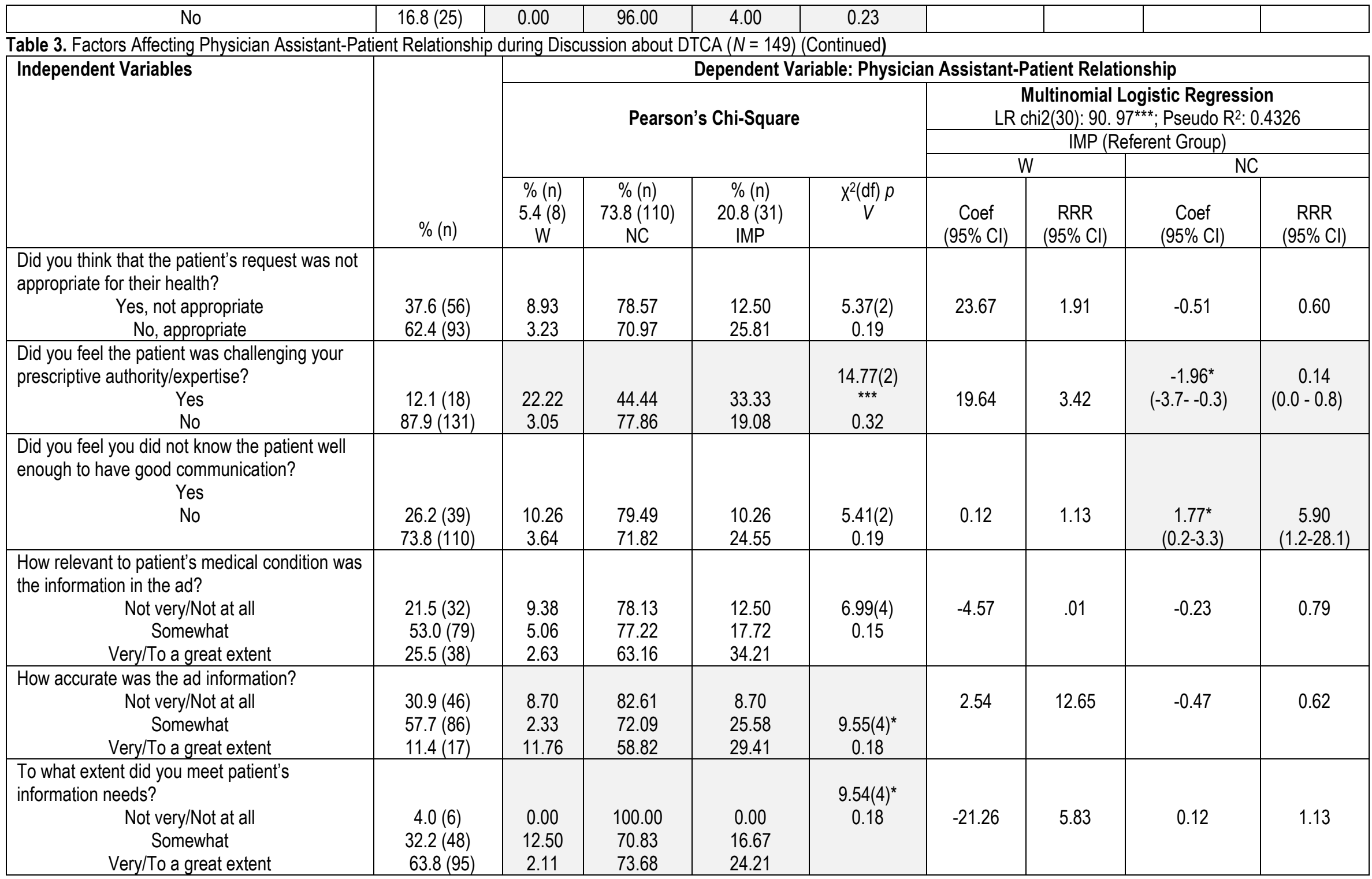


$X^{2}$ (df) $P=$ Chi-squared (degrees of freedom) $p$ value; $V=$ Cramér's $V ;{ }^{*} p<.05 ;{ }^{* *} p<.01 ;{ }^{* *} p<.001$; Coef.=The estimated multinomial logistic regression coefficient; RRR=Relative risk ratio for multinomial logit model; LR chi2=Likelihood Ratio Chi-Square; Pseudo R2=McFadden's pseudo R-squared; W=worsened/worsened much; NC=no change, IMP=improved/improved much; $\mathrm{Cl}=$ confidence interval.

Table 4 Effects of DTCA on Time Efficiency of Visit: Chi-Squared Analysis and Multinomial Logistic Regression $(N=149)$

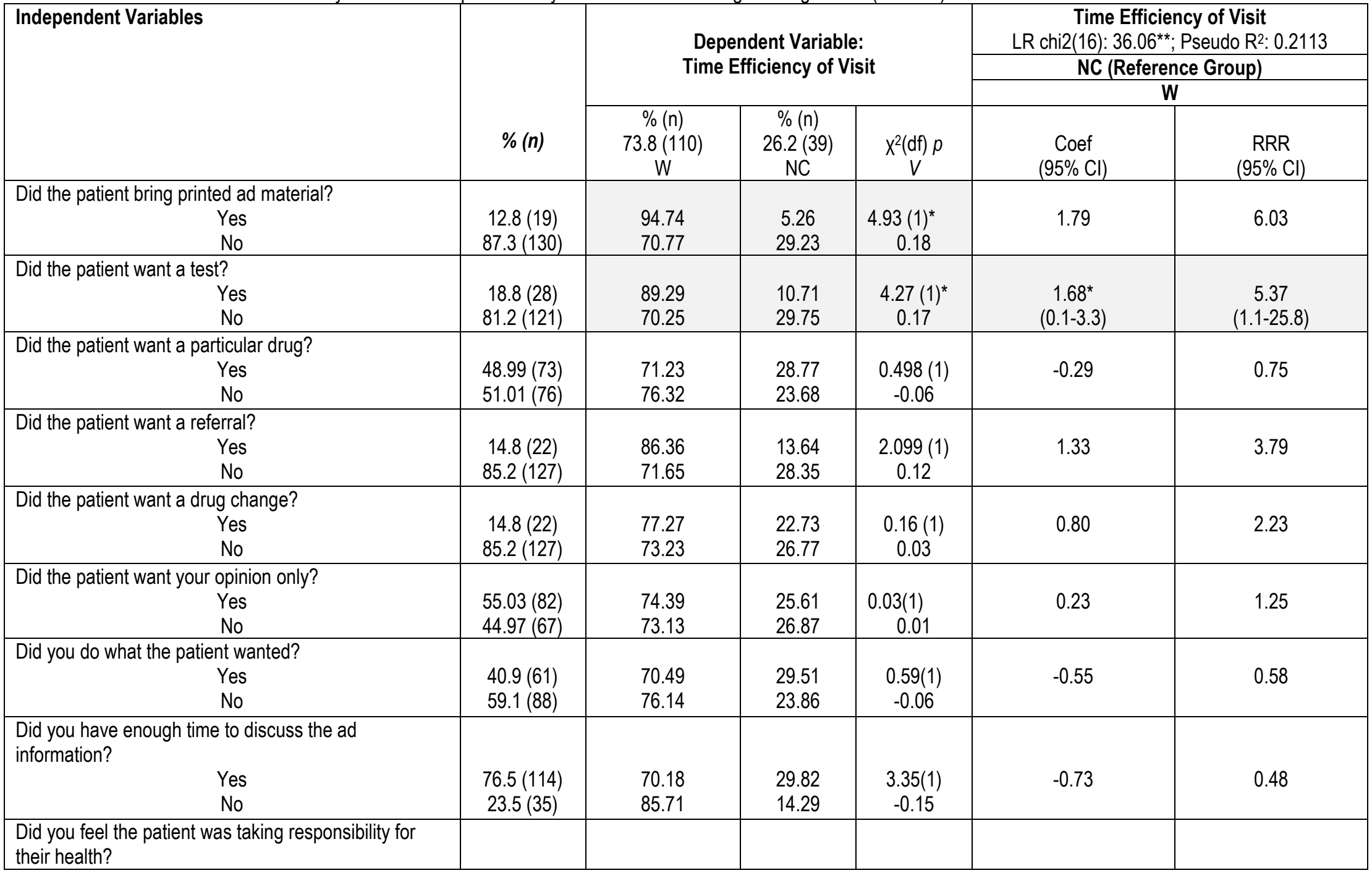

(c) The Internet Journal of Allied Health Sciences and Practice, 2020 


\begin{tabular}{|c|c|c|c|c|c|c|}
\hline Yes & $83.2(124)$ & 72.58 & 27.42 & $0.59(1)$ & 0.12 \\
No & $16.8(25)$ & 80.00 & 20.00 & -0.06 & 1.12 \\
\hline
\end{tabular}

Table 4 Effects of DTCA on Time Efficiency of Visit: Chi-Squared Analysis and Multinomial Logistic Regression ( $N=149)$ (Continued)

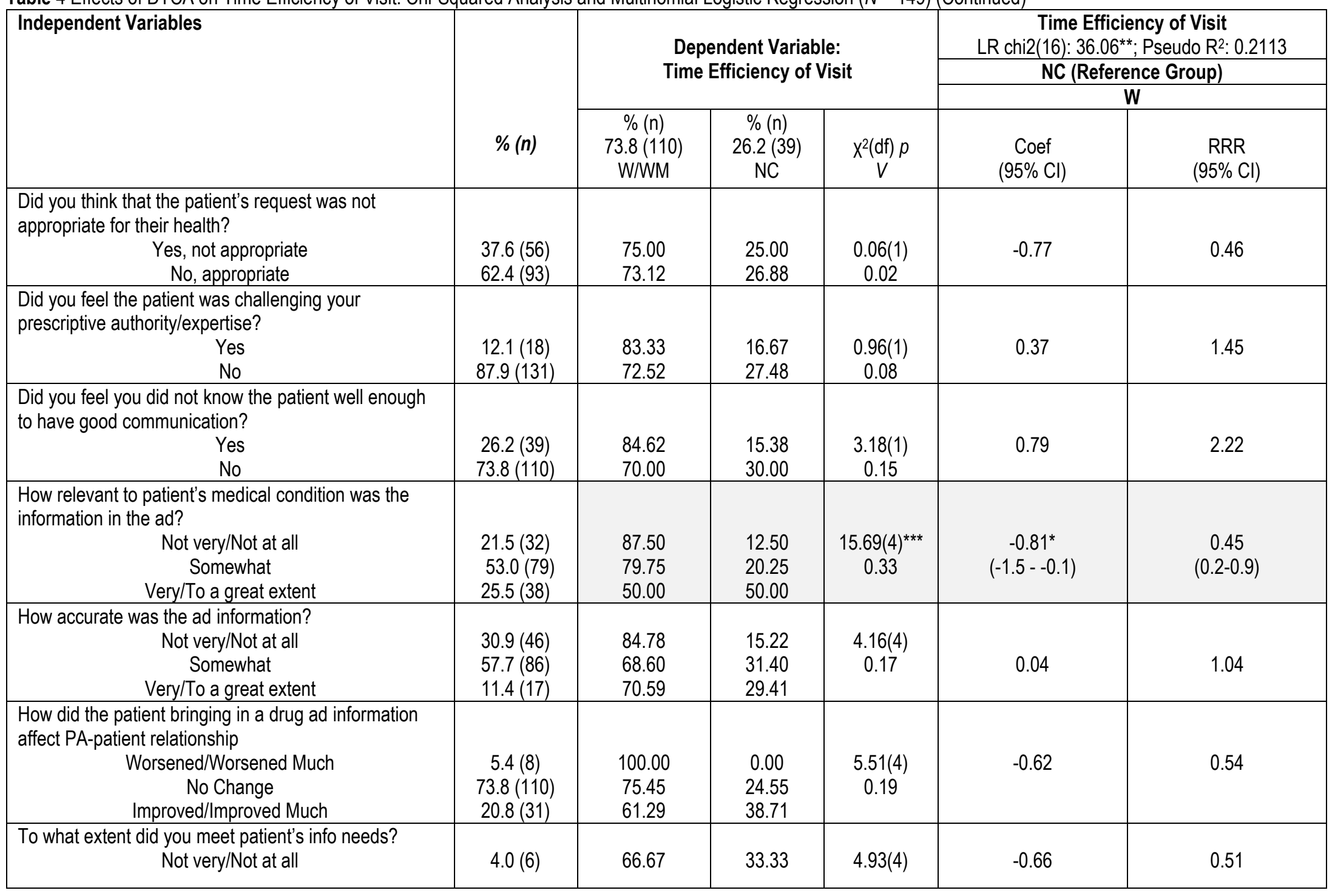

(0) The Internet Journal of Allied Health Sciences and Practice, 2020 


\begin{tabular}{|c|c|c|c|c|c|c|}
\hline Somewhat & $32.2(48)$ & 85.42 & 14.58 & 0.18 & & \\
Very/To a great extent & $63.8(95)$ & 68.42 & 31.58 & & & \\
\hline
\end{tabular}

$\mathrm{X}^{2}$ (df) $\mathrm{P}=$ Chi-squared (degrees of freedom) $p$ value; ${ }^{*} p<.05 ;{ }^{* *} p<.01 ;{ }^{* * *} p<.001 ; V=$ Cramér's $V$. Coef. =The estimated multinomial logistic regression coefficient; RRR=Relative risk ratio for multinomial logit model. $\mathrm{W}=$ worsened/worsened much; $\mathrm{NC}=\mathrm{No}$ change. $\mathrm{Cl}=$ confidence interval. 